\title{
Sexualidade infantil no contexto escolar: um desafio aos educadores
}

\author{
Child sexuality in the school context: a challenge to educators
}

La sexualidad infantil en el contexto escolar: un reto para los educadores

Nandra Martins Soares

ORCID: https://orcid.org/0000-0002-0224-9083 Universidade Estadual do Oeste do Paraná, Brasil E-mail: nandrasoares@yahoo.com.br

Fabrício Duim Rufato

ORCID: https://orcid.org/0000-0002-0514-3882 Universidade Estadual do Oeste do Paraná, Brasil E-mail: fabricio-rufato@hotmail.com

Elisabeth Rossetto

ORCID: https://orcid.org/0000-0002-4581-2446 Universidade Estadual do Oeste do Paraná, Brasil E-mail: erossetto2013@gmail.com

\begin{abstract}
Resumo
O objetivo deste estudo é entender quais as dificuldades enfrentadas pelos professores da educação infantil acerca da sexualidade no contexto escolar. Como recursos metodológicos, utilizou-se a abordagem qualitativa por meio de uma pesquisa de campo, com a aplicação de uma entrevista semiestruturada. Participaram da pesquisa cinco educadoras de um Centro Municipal de Educação Infantil (CMEI) do Município de Foz do Iguaçu - PR. Os dados foram analisados à luz da análise de conteúdo. A partir dos resultados, compreendeu-se que as professoras da educação infantil enfrentam dificuldades relacionadas às manifestações sexuais dos alunos, uma vez que, a falta de formação acadêmica e continuada destes profissionais, causa sentimento de insegurança frente a esta temática. Outra dificuldade enfrentada pelas educadoras está relacionada ao âmbito familiar da criança, visto que há grande resistência em falar e discutir sobre a sexualidade, o que se torna uma barreira na abordagem desse tema no contexto educacional. Desse modo, considera-se que a consolidação de discussões em espaços acadêmicos, a implementação de disciplinas e técnicas interventivas nas grades curriculares dos cursos que se propõem formar professores; assim como o aprofundamento no conhecimento do desenvolvimento infantil; e investimentos na formação continuada são ações necessárias para a construção de práticas no estudo sobre a sexualidade infantil.
\end{abstract}

Palavras-chave: Sexualidade infantil; Formação de professores; Escola; Família.

\begin{abstract}
The present study aims to understand the perception and difficulties faced by teachers of early childhood education about sexuality in the school context. Five educators from a Municipal Center for Early Childhood Education (CMEI) in the Municipality of Foz do Iguaçu - PR participated in the research. As methodological resources, the qualitative approach, the field research, was used, and a semi-structured interview was applied. The data were analyzed in the light of content analysis. From the results, it was understood that teachers of early childhood education face difficulties related to the sexual manifestations of children, since the lack of academic and continuous training of these professionals causes feelings such as insecurity and fear. In addition to presenting a simplistic representation of child sexuality, reducing it to the biological aspect, supporting a complex concept in their own personal beliefs and values. Another difficulty faced by the educators is about the family's understanding of child sexuality, which becomes a barrier in approaching this theme in the educational context, as there is resistance in the family about the subject. The consolidation of discussions in academic spaces, the implementation of disciplines and interventional techniques in the curriculum of courses; deepening the knowledge of child development; the continuous training of teachers are necessary actions for the construction of practices in the study of child sexuality.
\end{abstract}

Keywords: Child sexuality; Formation of teachers; School; Family.

\section{Resumen}

El presente estudio tiene como objetivo comprender la percepción y las dificultades que enfrentan los maestros de educación de la primera infancia sobre la sexualidad en el contexto escolar. Cinco educadores del Centro Municipal de Educación Infantil (CMEI) en el Municipio de Foz do Iguaçu - PR participaron en la investigación. Como recursos metodológicos, se utilizó el enfoque cualitativo, la investigación de campo y se aplicó una entrevista semiestructurada. Los datos se analizaron a la luz del análisis de contenido. A partir de los resultados, se entendió que los maestros de la primera infancia enfrentan dificultades relacionadas con las manifestaciones sexuales de los niños, 
ya que la falta de educación académica y continua de estos profesionales provoca sentimientos como la inseguridad y el miedo. Además de presentar una representación simplista de la sexualidad infantil, reduciéndola al aspecto biológico, apoyando un concepto complejo en sus propias creencias y valores personales. Otra dificultad que enfrentan los educadores es la comprensión de la familia de la sexualidad infantil, que se convierte en una barrera para abordar este tema en el contexto educativo, ya que existe una resistencia en el contexto familiar sobre el tema. La consolidación de discusiones en espacios académicos, la implementación de disciplinas y técnicas de intervención en el currículo de los cursos; profundizar el conocimiento del desarrollo infantil; La formación continua de los docentes son acciones necesarias para la construcción de prácticas en el estudio de la sexualidad infantil.

Palabras clave: Sexualidad infantil; Formación de profesores; Escuela; Familia.

\section{Introdução}

Há séculos a sexualidade infantil é considerada um tabu. Primeiramente, esse fato aconteceu devido à dificuldade de compreensão entre os termos "sexo" e "sexualidade" que eram pouco compreendidos até meados do século XIX e início do século XX. Acreditava-se que a sexualidade estava ligada a conteúdos impuros, visão esta defendida pelos preceitos religiosos que consideravam as crianças como seres inocentes - angelicais. Mas foi a partir do início do século XX que Freud (1912/1996) em três ensaios sobre a teoria da sexualidade ${ }^{l}$ considerou o desenvolvimento infantil estreitamente relacionados aos aspectos sexuais, ou seja, determinava que a sexualidade humana é constituída a partir do nascimento e o desenvolvimento da personalidade está ligado as pulsões sexuais.

Assim, esta temática é um grande desafio para os pais e principalmente para os educadores que vivenciam este tema no contexto escolar, tanto no manejo como na orientação de dúvidas. No decorrer do desenvolvimento da criança é natural surgir curiosidades sobre as mudanças corporais, interesse pelo seu corpo e pelo do outro, como também a busca de informações sobre o processo do seu nascimento. Na infância, é frequente a criança explorar o corpo, uma vez que este é um momento de descoberta. Portanto, são essas curiosidades e as relações familiares que despertarão na criança a diferença entre o masculino e o feminino, ou seja, do corpo sexuado (Porto, 2010; Silva \& Iglesias, 2021).

A sexualidade vai se constituindo desde o nascimento a partir das relações que o bebê estabelece com seus pais e as pessoas que o cuidam. Sigmund Freud (1856-1939), alega que as experiências e práticas sexuais são constituintes da personalidade e delinearão a condução da vida adulta do sujeito. Essas alegações abalaram a comunidade científica do início do século XX, uma vez que sua teoria enunciava que a personalidade era desenvolvida por meio de vários estágios, que consideravam impulsos e instintos sexuais como elementos principais na formação do sujeito, o que mais tarde Freud nomeou de estágios psicossexuais do desenvolvimento (Schindhelm, 2011).

A psicanálise freudiana foi a que mais adentrou nas teorias do desenvolvimento sexual infantil. Para Freud (1912/1996) o corpo da criança é erotizado desde o seu nascimento, pois é a partir do toque, da relação simbólica entre mãebebê que todo o corpo passa por esse processo. Assim, o autor postula as fases de desenvolvimento sexual - fase oral, anal, fálica, latente e genital, onde ocorrem do nascimento até a fase da adolescência.

Alguns teóricos colocam os estágios de desenvolvimento pelo qual a criança passa composto por uma ordem crescente - primeiro, fase oral, após concluída, a anal e assim sucessivamente. Porém esta afirmação não está coerente com os estudos psicanalíticos, pois Freud refere-se as fases a partir dos traços mnêmicos ${ }^{2}$ no sujeito e que dão origem a linguagem ao significado e sentido, uma marca primária que remete a um novo sentido - secundário que definem a personalidade. Então as fases acontecem simultaneamente em sua ordem e continuam por toda a vida, ou seja, acumula-se uma na outra, não há uma interrupção, a erotização ocorre e fica fixada na psique do sujeito. Por exemplo, a fixação na fase oral, pode gerar pessoas

\footnotetext{
1 Três Ensaios sobre a Teoria da Sexualidade é uma obra de 1905 de Sigmund Freud, em que o autor aprofunda a sua teoria da sexualidade e do desenvolvimento psicossexual, em particular, na sua relação com a infância.

2 É uma “forma especial de marca mnêmica que o infante aprende no vínculo com sua mãe, como fruto da transformação da 'alteração interna' (expressão das emoções, grito, inervação vascular). Devido a resposta frente à mãe, que dever ter o 'assistente estranho' (a figura materna), essa simples forma de descarga afetiva vai se transformando em chamado, adquirindo assim significado, ali, e na notícia do próprio grito que também pode surgir da vivência de dor, forma-se a base sobre a qual vai se originar a linguagem propriamente dita.” (Dicionário de Psicanálise)
} 
fixadas em prazeres orais, como a comida, consumo de bebidas, cigarro, doces, entre outros.

Contudo, é na fase fálica, em torno do terceiro/quarto ano de vida que a criança já possui certa maturidade para reconhecer suas genitálias, e a sensação de prazer ao tocá-las. Esse momento desperta curiosidades e uma busca na sensação de prazer. É também neste período que a criança se depara com a castração, ou seja, internaliza a proibição de sentir o prazer de forma egóica. Trata-se de um período difícil para as crianças e crucial para determinar a formação dos sintomas que ele carregará para lidar com a castração - formação das estruturas de personalidade, neurose ou psicose.

Nas décadas de 20 e 30 do século XX diversos movimentos propunham discutir questões com relação a sexualidade no ambiente escolar. A partir de concepções eugenistas e higienicistas defendiam uma educação sexual para combater doenças e problemas sociais na época, além de transmitir conteúdos sobre a evolução das espécies animais e do homem.

Todavia, a Igreja Católica detentora do saber e do monopólio sobre as escolas, agia de forma repressiva a esse movimento. Concomitante, o golpe militar na década de 60 favoreceu os construtos de uma educação da moral e bons costumes, e alegavam que educação sexual era comparada a uma sexualização precoce do infante (Guimarães, 1995).

Os movimentos, defensores da educação sexual preconizam o ensino de acordo com as fases de desenvolvimento e maturação, acreditando que se pode trabalhar com questões sexuais na infância a partir de conhecimentos científicos de acordo com a fase de desenvolvimento que a criança se encontra, de forma que o sujeito passe a verbalizar e compreender seu corpo biológico, desejos, sexualidade, diminuindo a repressão e problemas decorrentes a este assunto que até então não podia ser expressado e que constituem a personalidade.

Neste contexto vale destacar a contribuição de Lev Semionovitch Vigotski (1896-1930), que traz o conceito de Pedologia ${ }^{3}$, na qual enfatiza que deve-se analisar o desenvolvimento da infância a partir do meio que a criança vive, não como uma mera circunstância do desenvolvimento, mas abordá-lo a partir da perspectiva de qual relação existe entre a criança e o meio em determinada etapa do desenvolvimento. Pois, cada situação vivenciada se distingue de acordo com as diferentes faixas etárias, por exemplo, as falas das pessoas ao redor podem ser a mesma quando a criança tem seis meses, ou um ano e seis meses, a quantidade de palavras que a criança percebe, o caráter da linguagem refere ao seu atual nível de desenvolvimento, ou seja, a fala pode ser a mesma em ambos períodos, porém a compreensão não (Vigotski, 2001). Esse conceito vigotskiano contribui para o entendimento das fases do desenvolvimento infantil e abre para a discussão de como educar a partir do nível de maturidade que o aluno se encontra.

Contudo, diante da complexidade da sexualidade na infância, Leão, Ribeiro, Bedin (2010) apontam que nos últimos anos não houve incentivo nem iniciativas oficiais regulares e sistemáticas que oferecessem aos professores oportunidades de formação e/ou discussão sobre a educação sexual na Pedagogia, licenciaturas ou em educação continuada, nem mesmo consta na grade curricular de formação inicial. Com isso, no universo escolar, o educador se defronta com empasses que não lhe foram ensinados durante sua formação acadêmica.

A sexualidade vem se mostrando como um dilema nos primeiros anos dentro da escola, porque é neste meio que ocorrem as descobertas do corpo e a comparação com o corpo do outro. Desta forma, é necessário que o professor saiba lidar com esse assunto, assessorando o aluno no esclarecimento de dúvidas (Peres \& Pereira, 2012). Contudo, o trabalho com a sexualidade e educação sexual, além de não haver preparo dos professores, geralmente tem como resistência a falta de conhecimento, o preconceito, o tabu e a discriminação.

As reações e atitudes dos professores diante de um comportamento inesperado do aluno, como a masturbação infantil ou a um questionamento sobre o descobrimento do seu próprio corpo, pode gerar desconforto ou até ansiedade, fazendo com que esse profissional haja por impulso e reprima essa criança, podendo desencadear problemas no desenvolvimento da

\footnotetext{
${ }^{3}$ Estudo sistemático da vida e do desenvolvimento das crianças.
} 
sexualidade e interferindo não só na infância como também na adolescência e na vida adulta. E atualmente não é raro os pais verem a instituição de ensino como uma aliada para ajudá-los diante de questionamentos, trazidos pelos filhos a respeito da sexualidade. É importante que as primeiras orientações sejam realizadas pelos pais, e esse trabalho deve ser continuado na escola, pois é nesse contexto que a criança ampliará seu círculo social e surgirão mais curiosidades, mas este movimento não irá substituir e nem mesmo concorrer com a função familiar e sim acrescentar.

Contemporaneamente esta temática tem ganhado espaço nas discussões pedagógicas devido a problemas sociais que vem ocorrendo cada vez com maior frequência, por exemplo, gravidez na adolescência, casos de homofobia, diferenças de gênero, doenças sexualmente transmissíveis e o abuso sexual infantil. Porém, ainda é um grande desafio para a maioria dos educadores articular essa temática de forma que respeite as fases do desenvolvimento infantil e maneiras didáticas de trabalho, além da superação da compreensão do tema por um viés científico que vai de contramão as crenças religiosas. Deste modo, ressalta-se a importância de desenvolver estudos, pesquisas, intervenções e formações voltadas à orientação da sexualidade, para que pais e professores possam adquirir performances assertivas na condução do tema. Para tanto, esse estudo tem como objetivo compreender qual a percepção e as dificuldades enfrentadas pelos professores sobre a sexualidade na educação infantil.

\section{Metodologia}

Trata-se de uma pesquisa de abordagem qualitativa, com procedimentos de estudo de campo, sendo desenvolvida de maneira transversal. A pesquisa qualitativa busca compreender os significados, as crenças, e os valores dos fenômenos estudados para entender a realidade do indivíduo em seu contexto social, por meio da sua subjetividade (Minayo, 2010).

O procedimento de estudo de campo apresenta aprofundamento dos objetivos em análise, assim como uma maior flexibilidade, utilizando técnicas de observação. Esse processo tem ênfase em uma comunidade específica, voltada para a atividade humana, visando absorver as análises das situações do local (Gil, 2002).

A pesquisa ocorreu com cinco educadoras de um Centro Municipal de Educação Infantil (CMEI) da cidade de Foz do Iguaçu-PR. Para coleta de dados foi utilizada uma entrevista semiestruturada que abordou temas relacionados aos problemas enfrentados pelos professores da educação infantil sobre a sexualidade da criança, desde questões sobre sua formação acadêmica às situações que aconteceram e acontecem na escola. Para a seleção dos participantes, realizou-se um sorteio aleatório entre os 34 Centro Municipal de Educação Infantil (CMEI) do município, e assim selecionou-se um deles, e posteriormente a pesquisa foi apresentada aos possíveis participantes e verificado o interesse em participar do estudo.

Após o levantamento dos interessados, aconteceu um segundo sorteio e foram selecionados cinco participantes, correspondendo a $50 \%$ do número total de educadores do local. Sobre o tamanho da amostra e sua representatividade, Minayo (2017), ressalta que não há um consenso entre os teóricos sobre o número amostral em estudos qualitativos, diferentemente do que ocorre nas pesquisas quantitativas que usam métodos refinados para estabelecê-las, então optou-se por entrevistar apenas esta quantia de participantes.

Os dados foram coletados no período de setembro a outubro de 2019, e as entrevistas tiveram duração aproximada de 60 minutos cada. A produção desse estudo seguiu todos os preceitos éticos, sendo encaminhada ao Comitê de Ética em Pesquisa com Seres Humanos e aprovada sob parecer n ${ }^{\circ} 2.899 .320$.

Para a análise dos dados foi utilizada a ferramenta de análise de conteúdo, que segundo Bardin (2009) pode ser definida como um conjunto de instrumentos metodológicos, que propõem-se a analisar diferentes fontes de conteúdo (verbais ou não-verbais), e tem como objetivo alcançar indicadores que permitem uma conclusão a respeito da mensagem recebida por meio de categorias composta de três grandes etapas: pré-análise, onde é feita a sistematização das ideias iniciais, estabelecendo indicadores para a interpretação das informações coletadas, chamada a fase de organização. Segundo é realizado a exploração 
do material, que consiste na construção das operações de codificação, considerando os recortes do texto em unidades de registro. Por fim, o tratamento dos resultados e interpretação, nessa terceira fase é feita a categorização, que se dá através da classificação e agregação das informações em categorias simbólicas ou temáticas, com um posterior reagrupamento em função de características comuns (Bardin, 2009).

Em relação ao estudo bibliográfico buscou-se comtemplar autores clássicos que discutem a sexualidade e o desenvolvimento infantil, como também autores que problematizam o tema na contemporaneidade.

\section{Resultados e Discussão}

Para melhor compreensão dos resultados, foram estruturados nas seguintes categorias de análise: Representação da Sexualidade Infantil; Manifestações da Sexualidade Infantil; Formação dos Educadores sobre a Sexualidade Infantil e, Família e Sexualidade. Cada uma dessas categorias temáticas aprofundará a discussão acerca dos resultados obtidos pelos professores entrevistados.

\section{Representação da sexualidade infantil}

Durante as entrevistas, percebeu-se que três educadoras compreendem a sexualidade voltada para o aspecto biológico, como revela as seguintes falas: "é a tendência de cada um ser mais masculino ou feminino"; "sexualidade infantil eu entendo como a criança saber o que ela é né, se sou menino ou sou menina, acredito que seja isso". O significado reducionista que as educadoras apresentam sobre a sexualidade, mostra a dificuldade de definir o tema considerando a totalidade do sujeito, uma vez que a sexualidade está presente em todo o desenvolvimento do ser humano, desde os primeiros anos de vida até a morte. (Rodrigues \& Wechsler, 2014). Bem como, para Freud (1912/1996) a sexualidade humana é amorfa, ou seja, não possui uma definição, ela é constituída a partir das relações simbólicas do sujeito com seu núcleo familiar, a partir da constituição do sujeito, e isto está aquém de poder ser interditado - cabe apenas ao próprio sujeito em sua estrutura psíquica definir seu objeto de desejo sexual, como também sua identificação de gênero.

No entanto, a visão biológica de representação da sexualidade, não é algo incomum, visto que a sociedade é marcada por crenças culturais distorcidas, associando a sexualidade apenas ao comportamento sexual ou biológico em si, e ligando-o a preconceitos, tabus e crenças.

Desse modo é necessário entender que o educador também faz parte desta sociedade que cristalizou essas crenças, e que seu pensamento tem apropriação histórica como sujeito cultural, ou seja, sua forma de educar no meio social está atrelado pela sua história de vida, e os preceitos definidos culturalmente por uma maioria na sociedade. A criança é inserida nessa contextualização que de forma não consciente se apropria do que é repassado. Ainda como exemplo desta representação, Costa e Venâncio (2015) em um estudo com doze educadores de escolas de Educação Infantil das cidades de Jataí e Catalão no estado de Goiás- BR, apuraram que 50\% dos participantes apresentaram um conceito abrangente sobre sexualidade, definindoa como "ternura, amor e sexo", já os outros 50\% descreveram a sexualidade apenas no aspecto biológico.

Se a sexualidade é constituída de um movimento histórico e social, a partir de construtos culturais de cada época, podemos dizer que esse tema está sendo transformado em uma nova perspectiva no século XXI. Devido aos movimentos como gays \& lesbian studies, movimentos de minorias e a liberdade de expressão fez com que as diversas maneiras de posição sexual e gênero florescessem na sociedade contemporânea. Consequentemente, estes movimentos contribuíram para a percepção das crianças sobre a sexualidade - o sexo saiu de uma condição reprimida para uma condição narcísica, ou seja, as pulsões sexuais estão rebeladas ao culto do corpo, aos olhares do Outro e a busca da perfeição.

Olhar para o desenvolvimento sexual infantil apenas pelo viés da biologia, limita a análise de completude do humano. Precisa-se ir além, compreender que o cultural e social ultrapassa o biológico, e que os comportamentos sexuais infantis 
correspondem a um processo de desenvolvimento e descoberta, na qual a criança nesta fase possui uma compreensão diferente dos adultos (Morais, Penna, \& Progianti, 2010).

Nesse sentido, apenas uma educadora apresentou um conceito mais amplo sobre a sexualidade infantil, "a sexualidade é o desenvolvimento da criança, a parte afetiva, o tocar, o pegar, o sentir, não o sexo em si”. Segundo Werner (2016) é no desenvolvimento infantil que o sujeito se constitui em sua singularidade e suas características são resultado de experiências que ocorrem desde o nascimento, a qual se intensificam quando o meio muda, incluindo-se o seu desenvolvimento sexual.

De acordo com Staub e Graupmann (2015) a sexualidade infantil pode ser notada por meio das brincadeiras, nos momentos espontâneos da criança, no contexto escolar com os colegas ou em casa com os familiares. Com isso, é possível pensar que a sexualidade no âmbito da infância, é manifestada através de vivências de prazeres intensos que a memoração do corpo não esquece.

Trata-se de um momento da vida significativo para a aquisição de conhecimento sobre o corpo e está relacionada à maneira do ser humano agir, pensar, comunicar e expressar-se, portanto, é formada por fenômenos como prazer, emoção e afetividade, pois é construída através das relações estabelecidas com a família e o social que definem o modo singular de cada sujeito agir no mundo (Spitzner, 2005).

\section{Manifestações da sexualidade infantil}

$\mathrm{Na}$ infância, a sexualidade revela-se quando a criança emite curiosidades, questionamentos, busca conhecer o seu corpo e o do outro, destacando as diferenças sexuais de cada um. O que marca esse estágio de vida é essa exploração corporal, sem as influências que a sociedade impõe (Maia, 2014). Isso se confirma nos discursos das educadoras "eles procuram, eles são curiosos, eles querem saber, eles percebem que o corpo do outro é diferente do deles, eles vão, eles mexem, eles tocam. 'Têm curiosidade pelo outro, às vezes na hora de ir ao banheiro, (...) de conhecer o corpo do outro".

O principal veículo de manifestação da sexualidade infantil é o corpo, desde o nascimento, a criança manifesta sua sexualidade a partir do prazer da sucção até o descobrimento do próprio corpo, e isso se manifesta de diversas formas, de acordo com o estágio do desenvolvimento de cada um. É comum carícias nas regiões genitais, a curiosidade sobre o corpo do outro, brincadeiras e também na imitação do comportamento de pessoas adultas (Brasil, 1998; Borges \& Bochi, 2021).

Uma das educadoras relata que já percebe nas crianças a manifestação de interesse pelo corpo do outro desde muito cedo "é a partir da hora que eles veem a diferença de um para o outro (...) quando eu to trocando os meus de um ano de idade, eu acho que a sexualidade começa ai, eles começam a perceber que não são iguais, até mesmo a partir do cabelo, eles começam a comparar o corpo". Freud (1996) assegura que o desenvolvimento da sexualidade se inicia no recém-nascido e estende-se por algum tempo, porém essa sexualidade da criança costuma exteriorizar-se aproximadamente entre os três ou quatro anos de idade.

Diante dessa demanda, faz parte do cotidiano do professor compreender a criança em seu desenvolvimento, e não suprimir ou rejeitar tais manifestações, e fazer as orientações adequadas a cada fase do desenvolvimento.

Destaca-se a fala de uma educadora, que ficou visível a negação em relação a sexualidade infantil, "então assim você quase não vê, eles têm 3 aninhos, e quase não vê curiosidade, é difícil uma criança olhar a outra no banheiro".

Estudiosos do desenvolvimento infantil afirmam que a partir dos três anos de idade eles iniciam os questionamentos sobre gênero (menino não pode usar cabelo comprido, por exemplo) e nas manifestações sexuais (o beijo na boca e a masturbação) (Werner, 2016).

A criança conhece o mundo através da sua interação com o outro, por meio do contato com outras crianças descobre que há uma diferença corporal entre elas. No decorrer de seu desenvolvimento começa a compreender que existem também diferenças sociais e emocionais, e esse entendimento ganha maior clareza no decorrer da vida. Esse é o processo comum que 
faz parte da evolução de todos os indivíduos, é um momento em que a criança sente a necessidade de explorar coisas novas, partindo em busca de diversas fontes de informação (Silva, 2013).

No entanto, a escola é uma instituição enraizada historicamente e culturalmente nos preceitos da burguesia, e da classe dominante. Assim, pregam o ensino de controle das massas, agindo de uma forma não só biológica, mas também normativa, enaltecendo normativas cisgêneras, comportamento de alienação ideológica e religiosa, passando formas de negação, preconceito, e senso comum com a sexualidade, por exemplo, o que é comportamento do sexo masculino e feminino.

Pela questão cultural e pela falta de aprofundamento nesta temática, muitas vezes os professores ignoram as curiosidades das crianças sobre a sexualidade ou respondem suas perguntas de forma equivocada e fantasiosa, o que gera a construção de conceitos errôneos, insegurança, tensão e ansiedade. Nota-se então, grande despreparo para se trabalhar o tema no ambiente escolar, principalmente devido à influência de preconceitos que carregam de acordo com suas experiências e crenças (Oliveira \& Muzzeti, 2020).

Falar sobre a sexualidade infantil no universo escolar é um trabalho que compete ao educador, principalmente quando surge algum questionamento acerca do tema. Entretanto na prática docente o que se percebe são inúmeras dificuldades que comprometem a abordagem adequada acerca das manifestações infantis. E para compreender a temática precisa-se abranger o construto histórico e social da sexualidade do homem, identificando como as ideologias políticas predominantes interferem no processo da humanização.

Muitos estudos mostram que quando os professores se deparam com a sexualidade infantil, sentimentos como a insegurança, é eminente, pois há falta de conhecimento e manejo. (Werner, 2016). A afirmação do autor está presente no discurso das educadoras quando dizem que "as vezes a gente fica assustada e acaba assustando a criança também, pelo medo de chegar e falar ou acontecer alguma coisa (...) insegurança em quais termos devem ser utilizados com uma criança que tá criando conceitos na vida"; "eu acho que deve-se reprimir, cortar sem explicar, eu acredito que deva ser assim”; (...) você vai no automático, eles tiram pra fora o pênis, as vezes abaixa a calcinha, aí eu falo, guarda isso (...) as vezes aos gritos e acabo assustando eles querendo ou não"; "Eu sempre procuro desviar a atenção, nem reprimindo e nem estimulando". "A gente conversa dentro do limite que eles não podem ficar expondo o corpo pra todo mundo a gente tenta ensinar que pode machucar".

A curiosidade sobre a sexualidade surge por meio de questionamentos, brincadeiras e gestos, e muitas vezes os professores condenam ou refutam um determinado comportamento, e não entendem que a sexualidade tem sentido diferente para a criança, e acabam cometendo o erro de olhá-lo pela ótica do adulto. Para as crianças essa curiosidade sexual é natural e sadia, pois ajuda no desenvolvimento intelectual e emocional (Silva, 2007). Essas experiências sexuais corporais têm intima relação com a aprendizagem da criança, que por sua vez exerce papel fundamental para novas relações e novos aprendizados.

A sexualidade é inerente, vai além do ato sexual em si, ela se manifesta desde o momento do nascimento até a morte, de formas diferentes a cada etapa da vida e tem grande importância no desenvolvimento psíquico do sujeito, pois se relaciona com a busca do prazer, necessidade primária dos seres humanos (Freud, 1996).

Desse modo, podemos entender que a sexualidade é marcada pela cultura, afetos e sentimentos expressos no decorrer da história de cada pessoa, o que irá alicerçar suas crenças acerca desse comportamento, e se haver momentos de repressão, medo, insegurança ou até mesmo significados utópicos, isso irá impactar o desenvolvimento da sexualidade, de acordo com a singularidade de cada sujeito. Como também, a cultura predominante poderá atingir positivamente ou negativamente nas vivencias sociais e relações de trabalho que o sujeito adquire. Daí a importância de uma educação que supere os preceitos dominantes, e compreenda a sexualidade como traço da personalidade do sujeito inerente as crenças pré-estabelecidas.

Segundo Brasil (1998) faz parte do cotidiano do professor compreender a criança em seu desenvolvimento, e não suprimir ou rejeitar tais manifestações. Assim, apesar das dificuldades das educadoras em lidar com o assunto, é necessário que 
haja explicações e atenção sobre o que lhe foi questionado, o que torna imprescindível que os profissionais da área da educação tenham um conhecimento profundo acerca do desenvolvimento infantil; formações continuadas sobre a diversidade do contexto escolar, para que assim possam ser facilitadores e transformadores do mundo infantil.

\section{Formação dos educadores sobre a sexualidade infantil}

Apesar de atualmente existirem várias formas de abordar o assunto relacionado à sexualidade em sala de aula, tal tema ainda é tratado de maneira escassa, sendo desafiador para os educadores, pois muitos não têm a devida formação para discutir sobre esse assunto (Staub \& Graupmann, 2015).

Em um estudo realizado por Maia e Spaziani (2010) com professoras da educação infantil, observou-se que todas as participantes não tiveram a oportunidade de estudar conteúdos relacionados a sexualidade durante sua graduação. Além disso, também não foram disponibilizados formação continuada sobre o assunto, o que reflete em insegurança e despreparo na prática em sala de aula.

Nesta pesquisa também não foi encontrado dados positivos da formação profissional sobre sexualidade, em evidência nas seguintes falas "formação continuada não, procuro particularmente"; "a gente não vê essa temática nem no curso (...) a gente não tem uma abordagem expansiva para trabalhar esse tema"; "tem pouca formação sobre esse conteúdo e assim é uma coisa que eu não tenho estudado". É visto que os professores não são preparados e qualificados sobre o tema, e isso contribui para o fortalecimento de crenças pessoais sobre a sexualidade, uma vez que seja carente o aprendizado de como enfrentar curiosidades, expressões e gestos sexuais, os profissionais se apropriam de suas próprias convicções e da educação sexual familiar que tiveram ao longo de sua história de vida. As quais muitas vezes estão permeadas por preconceitos, tabus e dificuldades.

Em um estudo conduzido por Costa e Venâncio (2015) com doze educadores da Educação Infantil com objetivo de verificar à capacitação sobre a sexualidade infantil, $25 \%$ dos educadores afirmaram que receberam preparação para lidar com a sexualidade no contexto escolar, e 75\% acreditam que não. Não há dúvidas que é necessário refletir sobre qualidade na formação docente, pois preparar o profissional para executar um trabalho eficiente sobre a sexualidade na escola é um desafio atual e necessário (Bueno \& Moizés, 2010).

A instituição de ensino é o primeiro lugar, depois da família, que afloram as curiosidades e novas informações sobre a sexualidade, seja pelo colega ou pelo próprio contexto social do desenvolvimento que inicia maior compreensão do assunto por parte das crianças. A ausência deste tema na escola, vem se tornando um grave problema educacional e social, pois pode fazer com que jovens que não tiveram na infância a orientação necessária na escola, iniciem a vida sexual precocemente, o que pode resultar em doenças sexualmente transmissíveis, gravidez indesejada e abandono escolar (Bonfim, 2009).

Além disso, educar as crianças sobre sexualidade e gênero reduz a probabilidade de um abuso sexual acontecer. As crianças e adolescentes que aprendem sobre a educação sexual desde o momento que surgem as primeiras dúvidas ou inquietações sobre a sexualidade, estão mais preparadas para negar um abuso, pois muitas vezes, esses indivíduos acreditam estar recebendo carinho e afeto, ou seja, se receber orientações precocemente sobre esses aspectos, terá maior controle e conhecimento do seu corpo e das ações de outras pessoas sobre o mesmo (Nitahara, 2017).

Neste sentido, o investimento na formação dos educadores sobre a sexualidade infantil, é algo que vai além do simples conhecimento sobre esse tema, como estratégia de prevenção que deve começar logo na infância, por meio da educação sexual. Isso implicará na visão da criança sobre a sexualidade, e principalmente no discernimento do que é positivo e negativo nas atuações de outras pessoas sobre seu corpo.

A introdução de conteúdos sobre a educação sexual no currículo escolar, que tenham como objetivos preparar a criança para negar quando alguém quiser lhe tocar, saber a diferença entre contato e abuso, e não guardar segredos de pessoas 
desconhecidas são aspectos que podem impedir a ocorrência de abusos sexuais, facilitando também o diálogo, quando ocorrer alguma situação relacionada a sexualidade da criança (Vieira, 2006).

Diante dessa problemática, uma formação adequada pode enriquecer a atuação do docente, de modo que contribuirá com uma melhor preparação e, como resultado, o esclarecimento assertivo acerca das manifestações sexuais infantis (Rodrigues \& Wechsler, 2014). Mas para isso, é importante que seja implementado nos cursos de graduação o assunto sobre educação sexual, além de acesso a materiais didáticos sobre o assunto, palestras, reflexões, cursos e contato com outros profissionais especializados (Werner, 2016).

Precisa-se além de investir na educação dos professores e demais profissionais da escola consolidar a discussão e a contradição dos ideais culturais, para estes saberem cientificamente como as instituições sociais contribuem para a edificação da sociedade.

A constituição da criança perpassa pela linguagem e simbolização a partir do outro que o ensina a partir do seu exemplo. Assim, possuir profissionais críticos e cientificamente munidos dos conhecimentos sobre a sexualidade humana e suas diversidades, contribuiria diretamente para novas formas de simbolização das questões de gênero, raça, formatos corporais, entre outros. (Chaves \& Franco, 2020).

Entretanto as dificuldades resultantes da carência na formação dos educadores não são os únicos obstáculos para desenvolverem um trabalho de educação sexual com seus alunos, a postura da família e a sociedade alienada as normativas burguesas também podem ser um agravante.

\section{Família e sexualidade}

A educação sexual precisa ser uma ação conjunta entre família, escola e sociedade, mas devido as questões culturais e a falta de discussões sobre o tema nas instituições de ensino nem sempre isso acontece, e acaba sendo um impedimento para estratégias efetivas capazes de trabalhar a sexualidade de acordo com cada estágio do desenvolvimento infantil.

A respeito das dificuldades com a família as educadoras falam que "eu acho que tem uma barreira por causa do tema"; “eu não tenho esse tipo de conversa com a família (...), não cheguei a ter nenhum estímulo por parte da família”; "já houve reclamações de mães porque a professora falou pênis no meio da reunião, então tem que cuidar o que fala, as vezes falamos meio pejorativo, uso o termo "pipi" para os meninos. Dependendo como as mães levam essa questão isso acaba na diretoria"; "os pais ficam preocupados e é muito comentado isso, eles muitas vezes querem saber o que vamos ensinar para os filhos deles".

A partir do relato das educadoras fica evidente que a família não colabora na abordagem da sexualidade infantil, pois alguns pais mostram resistência em tratar o tema. De acordo com Oliveira et al. (2010) uma das maiores dificuldades das famílias está em não saber como abordar a temática, e não sabem usar as expressões corretas, somado ao medo de despertar ainda mais a curiosidade dos filhos sobre a sexualidade, acreditando que isso vai contra as questões de crenças e estigmas.

O acolhimento por parte da família com relação a esse tema é um fator importante, devendo ser fornecida desde o nascimento. No entanto, a instituição familiar nem sempre consegue exercer adequadamente essa tarefa e acaba transmitindo esse dever para a escola (Jardim \& Brêtas, 2006). Entretanto, ao mesmo tempo em que transferem para a escola a responsabilidade de educação sexual, os pais por muitas vezes, inseridos na visão conservadora, vão de contramão a atuação dos profissionais de ensino, limitando-os, causando grande impacto a relação com a escola e no desenvolvimento infantil.

O vínculo da família e da escola no processo de orientação sexual da criança é de grande relevância, pois é a instituição familiar o primeiro ambiente em que a criança adquire as referências iniciais, e a escola têm o dever de orientar e desfazer as distorções obtidas pela criança seja por meio da família ou por outras fontes (Rodrigues \& Wechsler, 2014).

As maiores angústias enfrentadas pelos educadores é a não aceitação dos pais, pois percebem que ainda não é o 
momento certo para que seus filhos aprendam a falar sobre sexualidade (Novak, 2013). Talvez esse entendimento que ainda rodeia os pensamentos dos genitores com relação à orientação sexual, é exatamente devido à falta de uma efetiva educação sexual ao longo de suas vidas, o que traz questionamentos e incertezas em relação aos filhos, e dessa forma, preservam a deseducação sexual (Ferreira, Paiva, \& Miranda, 2015).

As questões em volta do desenvolvimento sexual das crianças sempre foi alvo de grandes críticas no decorrer do surgimento das primeiras teorias sobre o tema. Na época quando Freud postulou a sexualidade infantil, enfrentou diversos confrontos entorno dela, sendo questionada até os dias atuais. O processo que a escola deve seguir é o da historicidade sobre essas relações entre teorias e crenças, como também analisar de forma consciente a cultura e o papel influenciador e formador das instituições sociais em relação a sexualidade. Assim, poderá realizar um trabalho crítico e consciente sobre o tema, analisando a dialética existente entre sociedade e instituição.

De forma geral, precisa-se entender que independentemente da idade, a sexualidade é vivenciada por todas as pessoas e as dúvidas, questionamentos e curiosidades devem ser esclarecidas e conversadas, de uma forma simples, clara e direta, para que tanto as crianças, quanto os adolescentes possam viver a sexualidade de forma digna (Gonçalves, Faleiro, \& Malafaia, 2013)

\section{Considerações Finais}

A partir das ideias abordadas neste estudo, evidencia-se que a sexualidade é de vital importância na vida dos sujeitos, inclusive na infância, pois está relacionada com a descoberta do corpo e com a formação da subjetividade. Desse modo, não é possível excluir essa temática da sala de aula. Entretanto, observou-se que os educadores não estão preparados para abordar de forma assertiva esse assunto no ambiente escolar.

A sexualidade por ser um conteúdo que ainda gera muita coerção nas pessoas, as manifestações das crianças acabam sendo ignoradas, reprimidas ou abordadas de forma equivocada e fantasiosa. Percebe-se que os profissionais da educação desconhecem a representação da sexualidade no desenvolvimento infantil, apresentando conceitos reducionistas e simplistas, amparados em suas crenças pessoais no momento de orientar e intervir na sala de aula.

Ficou enunciado que a sexualidade é percebida como um fenômeno temido pela escola e, quando se trata da sexualidade infantil, o problema aumenta, pois, a criança passa a ser vista muitas vezes como alguém que não está apta para receber instrução e que não pode ser educada sobre questões ligadas a sexualidade.

Em consequência disso, os professores se deparam com situações que não lhe foram apresentadas durante sua vida pessoal e acadêmica, e esse despreparo corrobora para a permanência da deseducação sexual, com estratégias repressoras, atitudes impulsivas, medo, insegurança e ansiedade.

Outro aspecto observado foi a falta de sintonia entre a família e a escola, na qual é um fator que dificulta a orientação sexual no ambiente educacional, pois os pais também apresentam resistência em abordar o assunto com os filhos e acabam determinando a conduta do educador. Por outro lado, há o medo de que haja informações precoces acerca da sexualidade e que possibilite uma emancipação sexual na criança. No entanto, considerando que a sexualidade faz parte do desenvolvimento humano desde o nascimento e é vivida de uma forma específica em cada fase da vida, é imprescindível abordar esse tema com as crianças seja no ambiente familiar ou escolar, fundamentado as orientações de acordo com o estágio do desenvolvimento infantil que se encontra, para que haja compreensão das ideias.

Há muitos fatores negativos gerados pela falta de informação e que, atualmente, crescem em níveis assustadores é o abuso sexual, a gravidez na adolescência, as doenças sexualmente transmissíveis, transgêneros, etc. Nessa perspectiva, investir em políticas públicas mais efetivas de formações de professores a respeito da educação sexual irá fomentar em estratégias realmente orientadoras e em um manejo mais assertivo e menos angustiante ao educador. 
A consolidação de discussões em espaços acadêmicos, a implementação de disciplinas e técnicas interventivas nas grades curriculares de cursos; o aprofundamento no conhecimento do desenvolvimento infantil; a formação continuada de professores, etc., enfim ações que viabilizem um diálogo e a construção de práticas no estudo sobre a sexualidade infantil e sua relação com a vida das crianças acarretará também nas mudanças de percepções pessoais dos próprios docentes, ajudando-os a desmistificar muitos preconceitos construídos ao longo de suas trajetórias de vida. Assim, recomenda-se novos estudos que aprofunda a temática envolvendo projetos de intervenção com professores e crianças, bem como estudos que discutam maneiras de abordar a sexualidade na educação infantil.

\section{Referências}

Abreu, I. S. (2017). Educação sexual em espaços da educação infantil. Dissertação (Programa de Pós-Graduação em Educação) - Pontifícia Universidade Católica de Goiás, Goiânia-GO. http://tede2.pucgoias.edu.br:8080/bitstream/tede/3811/2/IRENE\%20SILVA\%20DE\%20ABREU.pdf.

Altmann, H., \& Carvalho, G. E. F. (2012). Sexualidade na educação infantil: Entre o silenciamento e a vigilância. Campinas: Revista do Difere, 2(4). https://pt.scribd.com/document/130404436/Sexualidade-e-Educacao-Infantil-Texto-05

Araújo, R. M. B. T. (2010). Saúde na escola: ações de educação sexual e reprodutiva com a comunidade escolar. Dissertação (Mestrado) - Curso de Enfermagem, UFMG, Goiás. http://www.sbpcnet.org.br/livro/63ra/conpeex/extensao-cultura/trabalhos-extensao-cultura/extensao-cultura-pollyana-siqueiraqueiros.pdf

Bardin, L. (2009). Análise de conteúdo. Geográfica.

Brasil. (1998). Parâmetros Curriculares Nacionais: Terceiro e quarto ciclos do ensino fundamental. Brasilia, 436. http://portal.mec.gov.br/seb/arquivos/pdf/ttransversais.pdf

Brasil. (2012). Conselho Nacional de Saúde. Resolução N 466, de 12 de dezembro de 2012http://conselho.saude.gov.br/resolucoes/2012/Reso466.pdf

Borges, M. C., \& Bocchi, A. F. A. (2020). A sexualidade infantil em questão: processos de significação para a criança e seu corpo. Revista Humanidades \& Inovação, 7(27). https://revista.unitins.br/index.php/humanidadeseinovacao/article/view/5043

Boroto, I. G. (2016). Tempos e contratempos da sexualidade infantil: Concepções de professores da educação infantil. Universidade Federal do Espírito Santo. http://bdtd.ibict.br/vufind/Record/UFES_eab884e2ec6d7d8a544fb99a3d4cc187

Bueno, S. M. V., \& Moizés, J. S. (2010). Compreensão sobre sexualidade e sexo nas escolas segundo professores do ensino fundamental. Rev Esc Enferm USP. 44(1): 205-12. file:///C:/Users/Pc/Documents/artigos\%20tcc/compreensao\%20sobre\%20sexualidade\%20e\%20sexo\%20nas\%20escolar.pdf

Ciaffone, A. C. R., \& Gesser, M. (2014). Integração Saúde e Educação: Contribuições da Psicologia para a Formação de Educadores de uma Creche em Sexualidade Infantil. Psicologia: Ciência e Profissão, 34(3). <http://www.scielo.br/pdf/pcp/v34n3/1982-3703-pcp-34-03-0774.pdf

Chaves, M., \& Franco, A. F. (2020). Primeira Infância: educação e cuidados para o desenvolvimento humano. In: Martins, L. M., Abrantes, A. A., \& Facci, M. G. D. Periodização Histórico- Cultural do desenvolvimento psíquico. (2ª ed.) Campinas: Autores Associados, Cap. 5. 100-109.

Costa, E. R., \& Venâncio, C. (2015). Investigando a sexualidade infantil a partir do relato de educadores. Laplage em Revista (Sorocaba), 1(3), 130-142. http://www.laplageemrevista.ufscar.br/index.php/lpg/article/view/34/392

Ferreira, L. M. S., Paiva, M. C. C., \& Miranda, J. R. (2015). A percepção dos pais e mães sobre o trabalho de educação sexual na escola. In: II CONEDU: Congresso Nacional De Educação, 2, Campina Grande - Pb. Anais. http://www.editorarealize.com.br/revistas/conedu/trabalhos /TRABALHO_EV045_MD1_SA11_ID3128_28062015164925.pdf

Freud, S. (1996). Três ensaios sobre sexualidade. Imago.

Foucault, M. (1999). História da sexualidade I: a vontade de saber. (13a ed.), Edições Graal.

Gonçalves, R. C., Faleiro, J. H., \& Malafaia, G. (2013). Educação Sexual no Contexto Familiar: Impasses e Desafios. Holos. http://www2.ifrn.edu.br/ojs/index.php/HOLOS/article/viewFile/784/74.

Gil, A. C. (2002). Como elaborar projetos de pesquisa. (4a ed.) Atlas.

Gibson, L. E., \& Leitenberg, H. (2000) Child sexual abuse prevention programs: Do they decrease the occurrence of child sexual abuse? Child Abuse \& Neglect, 24(9), 1115-1125. https://www.sciencedirect.com/science/article/abs/pii/S0145213400001794

Guimarães, I. (1995). Educação Sexual na Escola: mito e realidade. Mercado de Letras.

Gusmão, S. B., Abreu, F. S. D., \& Pederiv, P. L. M. (2019). Educação para as sexualidades: Apontamentos a partir da perspectiva histórico-cultural de Vigotski. Revista Com Censo, 6. http://www.periodicos.se.df.gov.br/index.php/comcenso/article/view/662/429

Jardim, D. P., \& Brêtas, J. R. S. (2006). Orientação sexual na escola: a concepção dos professores de Jandira - SP. Revista Pesquisa Brasileira de Enfermagem Reben, 2(59), 157-62. <http://www.scielo.br/pdf/reben/v59n2/a07.pdf>. 
Maia, A. C. B. (2014). Sexualidade e educação sexual. Tese (Doutorado) - Curso de Psicologia, Faculdade de Ciências da Unesp, Bauru. https://acervodigital.unesp.br/bitstream/unesp/155340/3/unesp-nead_reei1_ee_d06_s03_texto02.pdf

Marques De C. L. A., M. R. P. R., \& Bedin, R. C. (2010). Sexualidade e orientação sexual na escola em foco: algumas reflexões sobre a formação de professores. Revista Linhas, 11(01), 36 - 52. www.revistas.udesc.br/index.php/linhas/article/view.

Minayo, M. C. S. (2001). Pesquisa Social: Teoria, método e criatividade. (18a ed.) Petrópolis: Vozes.

Morais, F. R. C., Penna, L. H. G., \& Progianti, J. M. (2010). A construção do conceito da sexualidade no contexto da enfermagem. Revista Cuidado é Fundamental. 1079(1071), 2-10. www.seer.unirio.br/index.php/cuidadofundamental/article/view/538/pdf_44

Novak, E. (2013). Dificuldades enfrentadas pelos professores ao trabalhar educação sexual nas escolas. Tese (Doutorado) - Curso de Ciências, Universidade Tecnológica Federal do Paraná, Medianeira. http://repositorio.roca.utfpr.edu.br/jspui/bitstream/1/2501/1/MD_ENSCIE_III_2012_20.pdf

Nitahara, A. (2017). Educação sobre sexualidade e gênero previne violência sexual. ttp://agenciabrasil.ebc.com.br/educacao/noticia/2017-05/educacao-sobresexualidade-e-genero-previne-violencia-sexual-diz

Odessa, M. W. (2016). Contribuições para a sexualidade infantil. Rev. latinoam. psicopatol. fundam., 19(3), 512-526. http://www.scielo.br/scielo.php?scrip $\mathrm{t}=$ sci_artt ext\&pid= S141547142016000300512\&lng=en\&nrm=iso

Oliveira, D. C., et al. (2010). Educação sexual infantil: A interação entre a família e escola como fator determinante para uma educação eficaz. Pedagogia em Ação, 2(1), 1-103. http://periodicos.pucminas.br/index.php/pedagogiacao/article/viewFile/4484/4609

Oliveira, M. F. C. de., \& Muzzeti, L. R. (2020). Sexualidade infantil: a relação entre Educação Sexual e a identidade de gênero. Revista on line de Política e Gestão Educacional, Araraquara, 24(3), 1825-1840. 10.22633/rpge.v24iesp3.14288. https://periodicos.fclar.unesp.br/rpge/article/view/14288

Porto, E. (2010). Sexualidade infantil: Refletindo o papel da escola. Tese (Doutorado), Universidade Estadual da Paraíba, Paraíba. http://www.editorarealize.com.br/revistas/conedu/trabalhos/TRABALHO_EV045_MD1_SA11_ID786_09082015203404.pdf

Peres, K. B. S., \& Pereira, M. S. C. (2002). A descoberta da sexualidade pelos alunos da educação infantil. TCC (Graduação) - Curso de Psicopedagogia, Universidade Candido Mendes Instituto de Pesquisas Sócio - Pedagógicas Pós-Graduação "latu Sensu", http://www.avm.edu.br/monop df/6/K\%C3\%81TIA\%20BARBOZA\%20DA\%20SILVA\%20PERES.pdf

Quirino, G. S., \& Rocha, J. B. T. (2012). Sexualidade e educação sexual na percepção docente. Educ. rev., 43, 205-224. http://www.scielo.br/scielo.php?script=sci_arttext\&pid=S0104-40602012000100014\&lng=en\&nrm=iso

Rodrigues, C. P., \& Wechsler, A. M. (2014). A sexualidade no ambiente escolar: a visão dos professores de educação infantil. Dissertação (Mestrado) - Curso de Pedagogia, Centro Universitário Unifafibe, Bebedouro. http://www.unifafibe.com.br/revistasonline/arquivos/cadernodeeducacao/sum ario/31/04042014074026.pdf

Rosa, L. M. G. (2016). Educação sexual na concepção de professores do ensino fundamental. Tese (Doutorado) - Curso de Ciências Naturais, Faculdade Unb Planaltina Licenciatura em Ciências Naturais, Planaltina. http://bdm.unb.br/bitstream/10483/15069/1/2016_LiviaMariaGulgielminDaRosa.pdf

Schindhelm, V. G. (2011). A sexualidade na educação infantil. Revista Aleph Infâncias, 5(16). https://periodicos.uff.br/revistaleph/article/view/39056/22494.

Spaziani, R. B., \& Maia, A. C. B. Educação para a sexualidade e prevenção da violência sexual na infância: concepções de professoras. Rev. Psicopedagogia, 32(97), p.61-71, 2015. http://pepsic.bvsalud.org/pdf/psicoped/v32n97/07.pdf

Silva, M. G. A. (2013). A Sexualidade Infantil: Desafios e Perspectivas no Currículo Escolar. Monografia (Especialização) - Curso de Pedagogia, Universidade de Brasília Faculdade de Educação, Brasília. http://bdm.unb.br/bitstream/10483/6231/1/2013_MariaGrazielaAssencoDaSilva.pdf

Kaminski da Silva, F., \& Rodrigues de La Iglesia, Y. (2021). Sexualidade infantil e a Educação: um diálogo com a teoria psicanalítica. Cadernos Acadêmicos Unina, 1(1), 12-22. https://doi.org/10.51399/cau.v1i1.36

Souza, M. M. (2017). Educação em sexualidade: A web educação sexual em ação. Dissertação (Mestrado) - Curso de Educação Escolar, Unesp, Araraquara. http://wwws.fclar.unesp.br/agenda-pos/educacao_escolar/4176.pdf

Spitzner, R. H. L. (2005). Sexualidade e adolescência: Reflexões acerca da educação sexual na escola. Dissertação (Mestrado) - Área de concentração aprendizagem e ação docente, Universidade Estadual de Maringá. http://www.ppe.uem.br/dissertacoes/2005-Regina_Spitzner.pdf

Staub, F. R. B. B., \& Graupmann, E. H. (2015). Educação infantil: uma abordagem sobre a sexualidade. Grupo de Trabalho - Diversidade e Inclusão. UNESPAR/UV. https://educere.bruc.com.br/arquivo/pdf2015/19270_8884.pdf

Vieira, N. M. (2006). Abusos sexuais a menores. TCC (Graduação) - Curso de Sociologia, Universidade de Coimbra, Coimbra, 2006. http://www4.fe.uc.pt/fontes/trabalhos/2005001.pdf

Vigotski, L. S. (2001). A construção do pensamento e da linguagem (P. Bezerra, trad.). Martins Fontes.

Werner, A. (2016). Professores da Rede Pública da Educação Infantil de Blumenau e a sexualidade das crianças de três a quatro anos: dificuldades, desafios e possibilidades. Monografia (Especialização) - Curso de Gênero e Diversidade na Escola, Universidade Federal do Paraná, Blumenau. https://acervodigital.ufpr.br/bitstream/handle/1884/51838/R-E-AMANDA WERNER.pdf?sequence=1\&isAllowed=y >. 